\title{
EL DIÁLOGO BIOÉTICO EN LAS TÉCNICAS DE REPRODUCCIÓN ASISTIDA
}

\author{
Francisco J. León Correa*
}

\begin{abstract}
Resumen: En las Técnicas de Reproducción Asistida (TRA) se enfrentan dos agentes morales en diálogo informado: el equipo médico y la pareja con problemas de infertilidad o esterilidad. Se entiende que el hijo es un bien humano básico para ambas partes.

Existe el peligro del cientificismo y del peso excesivo de la comercialización de estas técnicas. Además, es necesario establecer correctamente las condiciones para que ese diálogo médico-paciente respete las normas éticas racionales del discurso desde la perspectiva de la ética dialógica, y tener en cuenta los intereses y derechos del hijo en cuanto "el otro" presente-ausente. El personalismo y la ética de los bienes básicos pueden complementar el análisis de los dilemas éticos que conllevan las TRA.
\end{abstract}

Palabras clave: reproducción asistida, bioética, ética dialógica

\section{BIOETHICS DIALOGUE IN ASSISTED REPRODUCTIVE TECHNIQUES}

\begin{abstract}
In assisted reproductive techniques two moral agents are confronted in informed dialogue: the medical team and the couple with infertility or sterility problems. The offspring in this dialogue is a basic human rights for both parts.

There is danger of scientificism and of giving excessive importance to the commercialization of these techniques. Furthermore, it is necessary to establish the conditions to respect the rational ethical norms of discourse in the physician-patient dialogue, under the dialogical ethical perspective and to consider the interests and rights of the offspring as "the other" present-absent. The personalized bioethics perspective and the ethics of basic goods may complement the ethical dilemma's analysis related to assisted reproductive techniques.
\end{abstract}

Key words: assisted reproduction, bioethics, dialogical ethics

\section{O DIÁLOGO BIOÉTICO NAS TÉCNICAS DE REPRODUÇÃO ASSISTIDA}

Resumo: Nas Técnicas de Reproduçâo Assistida (TRA) nos encontramos com dois agentes morais que se enfrentam no diálogo informado: a equipe médica e o casal com os problemas de infertilidade ou esterilidade. Entende-se que nesse dialogo o filho é um bem humano básico para ambas as partes.

Existe o perigo do cientificismo e do peso excessivo da comercialização destas técnicas. Além disso, é necessário estabelecer corretamente as condiçóes para esse diálogo médico-paciente respeito das normas éticas racionais do discurso, desde a perspectiva da ética dialógica e levar em conta os interesses e direitos do filho enquanto "o outro" presente-ausente. O personalismo e a ética dos bens básicos podem complementar a análise dos dilemas éticos envolvidos nas TRA;

Palavras-chave: reprodução assistida, bioética, ética dialógica

* Doctor en Filosofía y Magíster en Bioética. Centro de Bioética, Facultad de Medicina, Pontificia Universidad Católica de Chile, Chile

Correspondencia: gibioetica@vtr.net 


\section{Introducción}

Existen muchos estudios recientes acerca de Técnicas de Reproducción Asistida (TRA), sobre todo desde las consecuencias jurídicas de los contratos que se establecen y los límites jurídicos que éstos deben tener. Se enfrentan con gran fuerza bienes jurídicos protegidos por el Derecho -como son la vida, la filiación, los derechos de sucesión, los derechos del hijo- y los nuevos "derechos reproductivos", expresados en la libre elección de los procedimientos que los padres quieren usar para tenerlo. De ahí el enorme interés del Derecho por estos temas (1-3).

Se produce también un amplio debate entre los investigadores acerca de la eficacia de las diferentes técnicas -crecen las posibilidades con cada descubrimiento científico- y sobre el momento del inicio de la vida humana -cada vez conocemos más y mejor el desarrollo del embrión unicelular, las etapas previas a la implantación y los mecanismos que guían el desarrollo en los inicios de la vida humana. La ciencia puede proporcionar el conocimiento que sirva a una mejor comprensión filosófica: no es un tema de dominio exclusivo de la ciencia ni de la filosofía, por lo que ambas deben complementarse(4-6).

Han sido ampliamente analizados algunos de los problemas éticos que presentan estas técnicas, especialmente en lo que se refiere a los embriones congelados, a la experimentación con embriones "sobrantes", a su utilización para obtener "células madre" embrionarias $(7,8)$ y, también, a la legitimación ética de las técnicas. Para algunos, la manipulación técnica del proceso de reproducción es legítima por la finalidad buena que pretende; para otros, es inmoral dado que irrumpe en el ámbito íntimo de la vida sexual de la pareja y "cosifica" la vida humana embrionaria, o la destruye, en el caso de los embriones "sobrantes".

Hay además un fuerte debate acerca de la finalidad terapéutica de estas técnicas y de la posibilidad-realidad ya en algunos casos- de que se extienda una mentalidad eugenésica con motivo del desarrollo de las propias TRA(9-12). La demanda social y las leyes del mercado, impulsadas quizás por expectativas desmedidas, pueden llevar a la ciencia médica a extremos insospechados, que abren interrogantes éticos sobre la finalidad misma de la medicina como ciencia $(13,14)$.

Son más escasos los análisis éticos acerca de los fundamentos de la relación entre técnica, medicina y usuarios(15-17). En las TRA nos encontramos normalmente ante dos agentes morales -el equipo médico, por un lado, y los padres infértiles o estériles, por otro- quienes, mediante diálogo informado, establecen la utilización de una técnica médica con un fin determinado: proporcionar o tener un hijo. Se entiende que el hijo es un bien humano básico para ambas partes. En este artículo nos centraremos en este punto.

\section{La ilusión del cientificismo}

Según algunos médicos responsables de las TRA sólo la ciencia empírica podría darse a sí misma los criterios éticos para evaluar su actividad, ya que su autonomía respecto de otros campos del saber humano es absoluta. El equipo médico representa a la ciencia que, por vez primera, domina otro ámbito más: la biología de la reproducción. Debemos recordar -sobre todo ante las nuevas expectativas de investigación genética y reproductiva- que la ciencia necesita siempre un fundamento reflexivo (racional) sobre su propia finalidad para no convertirse en ideología; debe reconocer los intereses que han movido a la razón a producir ese saber para identificar también los criterios éticos de actuación que deben guiar esos intereses. "El cientificismo -en palabras de Adela Cortina- bloquea toda fundamentación de la moral (...) Si queremos tener objetividad científica, esto presupone la validez intersubjetiva de normas éticas. No tiene sentido exigir la neutralidad de la ciencia empírica, en nombre de la objetividad, sin presuponer que la objetividad debe alcanzarse (...) Si pretendemos que los logros científicos valgan intersubjetivamente tiene que ser posible que valgan intersubjetivamente las normas presupuestas en la comunidad de científicos, no que valgan subjetivamente, en virtud de una decisión prerracional. En ese caso, la ciencia sería decisionista” (18).

Todo argumento en el cual se reivindican derechos y se exigen deberes -toda ética y, también, la ética de la ciencia- debe descansar en una elaboración racional y no, en el mejor de los casos, en una ideológica petición de principios. El cientificismo, en virtud de su carácter subjetivo, no puede darse a sí mismo la regulación ética y exigir normas a quien no posea idénticos principios. La deliberación racional sí puede hacerlo. Y ello es especialmente necesario en el caso de la investigación biomédica sobre el inicio de la vida humana y la procreación. 


\section{Diálogo de consenso o diálogo racional}

Según el esquema de la bioética liberal actual, el procedimiento de fundamentar convencionalmente estas técnicas médicas en la vida pública debe ser mediante el mero consenso, y así se ha legislado en muchos países, incluso desde la imposición de las mayorías parlamentarias y con muy poco debate social y político previo.

Frente a esta posición, es imprescindible establecer un auténtico diálogo racional. Las críticas al consensualismo desde la ética del discurso son fundamentales. En Apel hay algunos argumentos claves para clarificar algunos de los actuales debates sobre las TRA(18, $p$. 155-159):

- La validez de las convenciones precisa de una base moral y exige, al menos, tener una información adecuada, "interlocutores válidos" informados y mantener las promesas.

- Las leyes que no pueden legitimarse moralmente pierden su crédito antes o después. El solo pacto estratégico no otorga legitimidad moral, sólo una universal utilización de los hombres como medios, como posibles piezas; algo muy diferente del respeto por la autonomía y el reconocimiento auténtico de los derechos comunes.

- La sola suma de las decisiones individuales (médicos-padres, o médicos-sólo mujer, en algunos casos permitidas por algunas legislaciones) no produce necesariamente una decisión racional. Si las decisiones privadas son a veces irracionales las de mayoría pueden serlo también.

- Finalmente, en palabras de Adela Cortina: "Un acuerdo democrático, basado sólo en el consenso fáctico, compromete sólo a los participantes y no vincula ni tiene en cuenta a cuantos, afectados por el acuerdo, no han participado en él (clases marginales, pueblos del tercer mundo, generaciones futuras)" $(18, p .95)$.

En bioética debemos avanzar hacia un acuerdo racional de interlocutores válidos que legitime las normas morales cívicas y, en concreto, las pautas éticas y legales que regulan las técnicas de fecundación in vitro con transferencia de embriones, la clonación, la investigación con células madre, entre otras. "Esta es quizá - propone Diego Gracia-la gran tarea que todos tenemos delante y que irá ganando importancia en los próximos años: la necesidad de asumir un tipo de racionalidad que permita la participación de todos los implicados en el proceso de deliberación de los problemas prácticos, en nuestro caso de los problemas morales"(19). Es imprescindible el diálogo racional como un instrumento de análisis y de profundización ética(20), y tener en cuenta a los afectados por los acuerdos, que en las TRA son, sobre todo, los padres y los hijos. Pero examinemos primero las condiciones del diálogo racional.

No se trata sólo de alcanzar acuerdo entre intereses egoístas o individuales, que pueden ser muy legítimos; no tendría interés racional -y no sería por tanto universalizable-si sólo se buscara el consenso porque favorece individualmente a quienes lo realizan. Debe tener validez intersubjetiva, con argumentos comprensibles y aceptables, defendidos mediante el discurso racional. De otro modo, todo argumento de derechos y deberes descansaría, en el mejor de los casos, en una persuasión sentimental que sólo vincularía a los participantes.

Si aspiran a un valor universal, las TRA requieren una aprobación racional y seguir un criterio ético, con un diálogo que se establezca:

- Sin limitar los temas y las personas participantes. Entrar a fondo en el debate sobre el estatuto del embrión humano, por ejemplo. O que la mujer pueda expresar su punto de vista acerca de estas técnicas, quizás en ocasiones sólo analizadas desde la postura "masculina" del dominio científico.

- Sin otra coacción que no sea la del mejor argumento y con racionalidad plena. Debemos dejar de lado posiciones esencialmente afectivas o basadas en el sentimiento. Por supuesto, es preciso considerar la angustia que supone la infertilidad para una mujer o una pareja, pero no es su "deseo" más o menos profundo del hijo lo que va a delimitar la legitimidad de los medios que use para conseguir ese buen fin.

- Con una búsqueda cooperativa de la verdad. En ciertos países ha habido muy poco diálogo previo para lograr consensos, muy poca cooperación entre todos para conseguir un acuerdo racional y razonable. Es necesario rechazar la imposición de legislaciones permisivas por parte de mayorías políticas, sin un debate político previo y en medio de campañas de comunicación que distorsionan -o al menos dificultan- esa búsqueda de la verdad.

\section{Ética dialógica y el hijo como "el otro"}

Adela Cortina ha profundizado en el concepto de persona como "interlocutor válido", aplicable de modo 
especial precisamente al ámbito de la bioética. Según ella, la mayoría de las decisiones en bioética deberían resolverse mediante el diálogo entre sujetos autónomos. "Autonomía en este caso significa madurez psicológica y ausencia de presiones externas (sociales) o internas (el dolor mismo), suficientes como para decidir de acuerdo consigo mismo. Y este "consigo mismo" puede precisarlo en primer lugar el paciente, en una situación psicológica adecuada, porque él tiene un acceso privilegiado a su propia subjetividad, a sus proyectos de autorrealización. Por eso creo necesario precisar este concepto médico de autonomía como una articulación de las dos nociones de autonomía y autorrealización a las que antes me he referido: lo universalizable es aquí el derecho del paciente a tomar decisiones porque tiene un acceso privilegiado a su subjetividad, a sus propios ideales de autorrealización. Y tiene derecho a ello porque desde una autonomía dialógicamente entendida, el paciente "es digno de", tiene derecho a ser tratado como un interlocutor válido" (21). Prosigue Cortina: "...la relación ha de ser dialógica entre dos sujetos autónomos, uno de los cuales tiene la capacidad y el deber de asesorar; el otro, el derecho a decidir sobre su propia concepción de bien, ya que él es el beneficiario del acto médico" $(21$, p. 238).

En el caso de las TRA, los acuerdos racionales comprometen no sólo a los participantes directos, sino también a todos aquellos afectados por el acuerdo aunque no hayan participado en él; por tanto, deben ser tenidos en cuenta por los "interlocutores válidos" presentes. El hijo es el "presente-ausente", cuyos intereses deben ser defendidos por los padres, ya tutores del hijo en el momento de ser concebido in vitro, no siempre desde el punto de vista legal pero sí desde las obligaciones éticas de la filiación y la maternidad. Y sus intereses también deben ser tenidos en cuenta por los médicos, que se deben al bien de sus pacientes. Por esta razón, la ética médica ha insistido en tantas ocasiones en el deber de salvaguardar la vida en su inicio: "No es deontológico admitir la existencia de un período en que la vida humana carece de valor. En consecuencia, el médico está obligado a respetarla desde su comienzo (...) Al ser humano embriofetal enfermo se le debe tratar de acuerdo con las mismas directrices éticas, incluido el consentimiento informado de los progenitores, que inspiran el diagnóstico, la prevención, la terapéutica y la investigación aplicadas a los demás pacientes"(22).
Desde la misma ética dialógica se está avanzando hacia una superación de la mera contraposición de principios éticos en confrontación, como a menudo se entiende en el principialismo. A propósito de las técnicas de clonación, Habermas apela a la responsabilidad hacia la especie y las generaciones futuras para evitar una "eugenesia liberal" (23), pero su prevención es también aplicable a las actuales discriminaciones eugenésicas presentes en algunas de las TRA. Maliandi complementa su propia interpretación de los cuatro principios clásicos con el principio de convergencia, como medio de solucionar los conflictos precisamente en el ámbito de la biotecnología $(24)^{1}$. Adela Cortina comenta los límites de la ética dialógica: "Si esta concepción 'transformada' de persona no 'sirve' de ayuda en problemas bioéticos, como podría ser el del estatuto del embrión, si sólo nos permite establecer un marco para las decisiones, que ha de ser complementado con argumentos de otras propuestas morales, no queda sino reconocer que cualquier propuesta ética que aceptemos por racional es limitada en su capacidad de respuesta a los retos morales, lo cual no exige descartarla por inválida, sino trazar cuidadosamente sus límites, de suerte que no se propase en sus atribuciones ni deje de cumplir las tareas para las que sí está capacitada" $(21$, p.240).

Para muchos de los temas implicados en las TRA hace falta ese recurso a otras propuestas morales, comenzando por el deber ético de maximización de los cuatro principios básicos de la bioética. El ideal ético no es simplemente conseguir la solución pacífica entre esos cuatro o más principios, sino tratar de alcanzar la armonía y maximización de ellos en la acción ético-clínica ${ }^{2}$, muy especialmente en lo que respecta a los posibles conflictos entre la autonomía de los padres y la técnica médica, por un lado, y los deberes de beneficencia y no maleficencia para con el futuro hijo, por otro.

En cuanto al debate sobre el estatuto del embrión humano, algunos sostienen un respeto ético diferenciado según el desarrollo biológico. Así podríamos "manejar

\footnotetext{
"La ética de la biotecnología padece la condición de que ninguno de sus principios puede cumplirse plenamente sin transgredir alguno de los otros. Es lo que la ética convergente expresa como 'incomposibilidad de los óptimos' y justifica la postulación de un quinto principio (al que corresponde considerar, más bien como un metaprincipio) representado por la exigencia de procurar el máximo equilibrio posible entre los cuatro. Se lo denomina principio de convergencia”.

León F. Bioética y justicia social en Latinoamérica. En: X Congreso Latinoamericano de Medicina Social. Actas del Congreso. Salvador de Bahía: 2007 (en prensa).
} 
blastocistos, cuidar embriones, y respetar fetos" (25). En esta misma línea, la ley española que regula la fecundación in vitro sostiene en su introducción que el embrión preimplantatorio es "un material biológico (...) grupo de células resultantes de la división progresiva del óvulo desde que es fecundado hasta aproximadamente catorce días más tarde"3, por lo que deduce la regulación jurídica de su protección desde estos supuestos "datos científicos". No podemos encontrar en el discurso científico respecto del desarrollo biológico los elementos valorativos del nuevo ser humano. La ciencia no puede demostrar si el embrión es o no persona, pero sí puede acercarnos a comprender la importancia del desarrollo de la corporeidad humana desde su inicio.

Pero la diferencia ética podría estar también en la dimensión relacional de la dignidad humana, con lo que pasaríamos de la lógica de la cualidad a la lógica de la relación: que el embrión sea considerado persona o una "realidad intermedia" es secundario, pues "no es óbice para que no se le trate con respeto y con dignidad (...) una dignidad humana y como tal abierta, incierta, exigiéndonos constantemente responsabilidad"(26). Aunque no es suficiente, la "presencia relacional" del embrión no deja de ser significativa para la ética y el respeto a la dignidad en el inicio del deseo de acudir a las TRA.

Tanto la corporeidad como la dimensión relacional juegan un papel importante en la valoración ética del embrión. Ambas entendidas filosóficamente y no como mero dato empírico aportado por la ciencia experimental. "El concepto de la corporeidad juega un papel clave en la determinación de la dignidad. El cuerpo humano no es un puro organismo material, sino lenguaje, expresión, relación con el mundo y con los otros, expresión de la interioridad (...) Consideramos que la dignidad debe extenderse a todo ser humano, que no pueden realizarse diferencias entre seres humanos y personas (...) la dignidad debe adscribirse a todo

\footnotetext{
"El material biológico (sic) utilizado es el de las primeras fases del desarrollo embrionario, es decir, aquel desarrollo que abarca desde el momento de la fecundación del óvulo hasta el nacimiento (sic) (...) Generalmente se viene aceptando el término "preembrión" -también denominado "embrión preimplantatorio" por corresponderse con la fase de preorganogénesis- para designar al grupo de células resultantes de la división progresiva del óvulo (sic) desde que es fecundado hasta aproximadamente catorce días más tarde, cuando anida establemente en el interior del útero -acabado el proceso de implantación que se inició días antes- y aparece en él la línea primitiva”. España: Ley de 22-11-1988, núm. 35/1988, sobre Reproducción Asistida Humana.
}

ser humano en tanto que ser potencialmente capaz de desarrollar actividades como el pensar, el amar y crear. Dicha atribución debe efectuarse a partir del momento en que existe la 'mínima suficiencia constitutiva' para desarrollar en el futuro tales actividades" (27), y en la determinación de esta corporeidad y capacidad relacional suficientes sí pueden ayudarnos las aportaciones científicas de todas las disciplinas humanas, no sólo las provenientes de la biología del desarrollo.

\section{La vida humana como bien básico de la persona}

Se debe complementar la ética del discurso con la de los bienes básicos, y con la visión antropológica y ética del personalismo filosófico. No deben ser mundos separados sino visiones complementarias y, desde luego, estar presentes en el diálogo bioético plural, desde el respeto mutuo.

La llamada "nueva escuela de derecho natural" parte de la fundamentación de los derechos de las personas, en lo que John Finnis llama "valores básicos", aspectos fundamentales del bienestar humano, "aquellas formas básicas de realización humana plena como bienes que se deben perseguir y realizar". Son aprehendidos y orientados por la razón práctica y se explican como bienes que perfeccionan al hombre y lo conservan unido en sociedad salvaguardando su dignidad. No son básicos para su existencia, sino para su subsistencia y perfeccionamiento personal y social. "Entre ellos, el bien de la vida no puede servir de medio para conseguir otros tipos de fines o bienes. La dignidad de la persona y la conjunción de todos los bienes que participan en esa realización integral del hombre son las que establecen el deber absoluto del respeto incondicionado al bien humano llamado 'vida"'(28).

Esta consideración tiene especial relieve en el debate ético sobre las TRA, en el cual puede ponerse en juego el bien de la vida humana para conseguir otros bienes como la paternidad o la maternidad. En este mismo sentido, Alfonso Gómez-Lobo analiza los "bienes humanos básicos" como complementarios de la racionalidad práctica, aplicándolos, entre otros temas, a la experimentación con embriones humanos. La vida es un bien humano básico -quizás el más básico en las etapas iniciales de desarrollo embrionario y fetal- que se da sin discontinuidad; "la consecuencia normativa de todo esto es que si los seres humanos somos esencialmente organismos de cierto tipo cuya existencia se extiende 
en el tiempo y si la norma moral que prohíbe matar se aplica a un ser humano de cualquier edad, entonces ésta cubre también a los seres humanos en su etapa más temprana, en su etapa embrionaria"(29).

En la mayoría de las TRA, la dignidad del embrión humano se reduce a la que conceden los padres o la sociedad, sin percibir que "todas las formas de dignidad se encuentran en la primera fuente, la dignidad puramente ontológica (...) Al privar al no nacido y a otras personas humanas de su vida, les privamos también de la posibilidad de alcanzar esa dimensión más profunda de su vocación de llegar a una dignidad más profunda que la mera de personas vivas"(30,31). Más allá de la discusión sobre la personalidad del embrión y de los problemas de respeto a la vida que plantea la fecundación in vitro, admitirla "significa reconocer la racionalidad moral de los intentos dirigidos a mejorar -y no sólo 'reparar'- la constitución biológica del Homo Sapiens" (32), con la duda acerca de quién podría establecer el criterio de perfección de una determinada constitución psicobiológica humana.

En el personalismo, el respeto a la dimensión biológica del hombre está esencialmente unido a la "afirmación de la persona por sí misma, como sujeto y objeto del amor", más allá de no utilizarla como un simple medio(33). Y esto se aplica a toda vida humana. La nueva vida humana surgida o que surgirá de las TRA nos exige ya -aunque aún no esté presente- no sólo la responsabilidad ante las generaciones o los sujetos humanos futuros(34), sino tenerla en cuenta en el diálogo bioético entre equipo médico y padres, tanto por su condición de "presente-ausente" como por el bien personal básico de la vida en juego.

\section{Referencias}

1. Gandra I. (Coord.) Direito Fundamental à Vida. São Paulo: Quartier Latin; 2005.

2. Ugarte JJ. El derecho de la vida. Bioética y Derecho. Santiago de Chile: Editorial Jurídica de Chile; 2006.

3. Massaglia MV. Nuevas formas de procreación y el Derecho Penal. Buenos Aires: Ad Hoc; 2001.

4. Beca JP. (Coord.) El embrión humano. Santiago de Chile: Mediterráneo; 2002.

5. Hidalgo MC. Análisis jurídico-cientifico del concebido artificialmente. Barcelona: Bosch; 2002.

6. Carrasco I. (Coord.) Identidad y estatuto del embrión humano. Madrid: EIUNSA; 2000.

7. VVAA. El destino de los embriones congelados. Madrid: Fundación Universidad Española; 2003.

8. Germán R. Losembrioneshumanos congelados: un desafiopara la bioética. Madrid: Ediciones Internacionales Universitarias; 2007.

9. Abellán, F. Selección genética de embriones. Entre la libertad reproductiva y la eugenesia. Granada: Comares; 2007.

10. Abellán F. Reproducción Humana Asistida y responsabilidad médica. Granada: Comares; 2001.

11. Ballesteros J. (Ed.) La Humanidad in Vitro. Granada: Comares; 2002.

12. Díaz de Terán MC. Derecho y nueva eugenesia: un estudio desde la Ley 35/88, de 22 de noviembre, de técnicas de reproducción asistida. Pamplona: EUNSA; 2005.

13. Cambrón A, et al. Reproducción asistida: promesas, normas y realidad. Madrid: Trotta; 2005.

14. Spar DL. Baby Business. Cómo el dinero, la ciencia y la politica condicionan el negocio de la infertilidad. Madrid: Urano; 2006.

15. Bestard J. Tras la Biologia: la moralidad del parentesco y las nuevas tecnologias de reproducción. Barcelona: Universidad de Barcelona; 2004.

16. Vila-Coro MD. Huérfanos biológicos. El hombre y la mujer ante la reproducción artificial. Madrid: San Pablo; 1997.

17. Pérez Monge M. La filiación derivada de técnicas de reproducción asistida. Zaragoza: Facultad de Derecho; 2002.

18. Cortina A. Ética Minima. 4a edición. Madrid: Tecnos; 1994: 93-94.

19. Gracia D. Como arqueros al blanco. Estudios de bioética. Madrid: Triacastela; 2004: 127.

20. Lolas F. Bioética. El diálogo moral en las ciencias de la vida. Santiago de Chile: Editorial Universitaria; 1998.

21. Cortina A. Ética aplicada y democracia radical. Madrid: Tecnos; 1993: 236-240.

22. Consejo General de Colegios Médicos de España. Código de Ética y Deontología Médica. Madrid; 1990: artículos 25.1 y 25.2.

23. Habermas J. El futuro de la naturaleza humana. ¿Hacia una engenesia liberal? Madrid: Paidós Ibérica; 2002.

24. Maliandi R. Etica: dilemas y convergencias. Cuestiones éticas de la identidad, la globalización y la tecnología. Buenos Aires: Biblos; 2006: 95-128. 
25. Masiá J. Manejar blastocistos, cuidar embriones, respetar fetos. En: Masiá J. (Ed.) Ser humano, persona y dignidad. Madrid: Desclée de Brouwer; 2005: 323-326.

26. Domingo T. Difícil dignidad. Cuestiones abiertas. En: Masiá J. (Ed.) Ser humano, persona y dignidad. Madrid: Desclée de Brouwer; 2005: 341-357.

27. Torralba F. La raíz de la dignidad humana. En: Masiá J. (Ed.) Ser humano, persona y dignidad. Madrid: Desclée de Brouwer; 2005: 245-262.

28. Saldaña J. El derecho a la vida. La defensa de Tomás de Aquino y de John Finnis. En: Gandra I. (Coord.) Direito Fundamental à Vida. São Paulo: Quartier Latin; 2005: 51-54.

29. Gómez-Lobo A. Los bienes humanos. Ética de la ley natural. Santiago de Chile: Mediterráneo; 2006: 127-131.

30. Seifert J. Dignidad humana. Dimensiones y fuentes en la persona humana. En: Borobia JJ, Lluch M, Murillo JI, Terrasa E. (Eds.) Idea cristiana del hombre. Pamplona: EUNSA; 2002.

31. Spaemann R. Personas. Acerca de la distinción entre "algo" y "alguien". Pamplona: EUNSA; 2000.

32. Chalmeta G. La dimensión biológica del hombre en el personalismo ético. Medicina y Ética 2007; 18(1): 15-26.

33. Wojtyla K. Mi visión del hombre. Hacia una nueva ética. Madrid: Palabra;1997: 315-316.

34. Jonas H. El principio de responsabilidad. Barcelona: Herder; 1995.

Recibido: 13 de junio de 2007.

Aprobado: 20 de julio de 2007. 